\title{
SPECII DE ECTOPARAZIȚI SPECIFICI ȘI COMUNI LA PĂSĂRILE DOMESTICE ȘI SĂLBATICE DIN REPUBLICA MOLDOVA
}

\section{Zamornea Maria, Erhan Dumitru, Rusu Ștefan, Chihai Oleg, Bondari Lidia, Coadă Viorica ${ }^{1}$, Botnaru Nicolai ${ }^{2}$}

Institutul de Zoologie al Ministerului Educației, Culturii și Cercetării, Chișinău, R. Moldova ${ }^{1}$ Universitatea de Stat din Tiraspol, Chișinău, R. Moldova

2Institutul de Fiziologie și Sanocreatologie al MECC, Chișinău, R. Moldova

\section{E-mail: mariazamornea@gmail.com}

https://doi.org/10.53937/9789975315975.68

\begin{abstract}
The aim of the paper was to highlight the interdependence between wild and domestic birds in the transmission of various forms of parasitic agents. Domestic poultry (hens, turkeys, ducks, geese) recorded an infestation of 13 species of malophagous (Cuclotogaster heterographus, Eomenacanthus stramineus, Goniocotes gallinae, Goniocotes maculatus, Goniades dissimilis, Menopon gallinae, Menacanthus pallidulus, Menacanthus cornutus, Lipeurus caponis, Chelopistes meleagridis, Anatoecus dentatus, Anatoecus icterodes). For hens were recorded 10 species of malophagous (Cuclotogaster heterographus, Eomenacanthus stramineus, Goniocotes gallinae, Goniocotes maculatus, Goniodes dissimilis, Menopon gallinae, Menacanthus pallidulus, Menacanthus cornutus, Lipeurus caponis, Chelopistes meleagridis), of which Chelopistes meleagridis species are occasional, 2 flea species (Ceratophylus gallinae, Ceratophylus hirundinis) and 3 gamma-acarian species (Dermanyssus gallinae, Dermanyssus hirundinis and Knemidocoptes mutans). It has been established that wild birds of hunting interest (pheasants, quails, geese, wild ducks) hane miximvasions with a wide variety of ectoparasites: 10 species of malophagous (Cuclotogaster cinereus, Goniocotes chrysocephalus, Goniodes colchici, Cuclotogaster heterographus, Eomenacanthus stramineus, Menopon gallinae, Menacanthus stramineus, Anaticola crassicornis, Anatoecus dentatus, Anatoecus icterodes, of which 9 species (Cuclotogaster heterographus, Eomenacanthus stramineus, Menopon gallinae, Goniocotes gallinae, Goniodes dissimilis, Lipeurus caponis, Anaticola crassicornis, Anatoecus dentatus are common for domestic birds, 2 flea species (Ceratophylus gallinae, Ceratophylus hirundinis) and 3 species of parasitic mites (Dermanyssus gallinae, Dermanyssus hirundinis and Knemidocoptes mutans), which have been established in domestic poultry.
\end{abstract}

Key words: polyparasitism, wild birds, poultry, hunting. 


\section{INTRODUCERE}

Valorificarea eficientă și cu continuitate a populaţiilor speciilor de interes vânătoresc implică cunoașterea cât mai amănunţită a modului de viaţă și a relaţiilor dintre populaţiile acestor specii și celelalte elemente ale ecosistemelor din care fac parte.

Parazitozele sunt cele mai frecvente boli întâlnite la păsările sălbatice și domestice, producând pierderi mari în randurile acestora. Prezenţa bolilor parazitare este neglijată de cele mai multe ori, cu toate că infestaţiile pot fi fatale la pui și păsările slăbite $[2,4,5]$. Componenţa paraziţilor a majorităţii păsărilor sălbatice, pot influenţa considerabil asupra dinamicii populaţiilor lor, mai ales pe parcursul intervalelor mari de timp. Numai în cazuri unice păsările sunt atacate doar de o singură specie de parazit. Acarienii gamazizi și unele specii de malofagi, care parazitează pe păsările domestice și sălbatice, îndeplinesc și rolul de vectori ai unor agenţi patogeni [3]. De aceea este destul de important de evidenţiat mixtinvaziile cu ectoparaziţi la păsările sălbatice, la care se menţin și se răspândesc, fiind una din problemele actuale ale parazitologiei și ecologiei contemporane.

\section{MATERIALE ȘI METODE}

În scopul evidenţierii interdependenţei dintre păsările sălbatice și cele domestice, în transmiterea diverselor forme de agenţi parazitari, au fost recoltate eșantioane biologice atât de la păsări sălbatice de interes cinegetic (fazani, prepeliţe, gîști, lebede, raţe), întreţinute în captivitate și în natură, cât și de la cele domestice (găini, curci, gîști, raţe).

Recoltarea probelor s-a efectuat individual și în grup. Au fost utilizate metode speciale de examinare a ectoparaziţilor la păsări după Dubinin M. [6] și „Luncașu M., Zamornea M. [1]. Ectoparaziţii au fost colectaţi de pe păsări vii, conform unui procedeu nou, care este mai informativ. Materialul colectat a fost examinat ulterior cu ajutorul lupei MEC-9 (ob.14x2) și a microscopului Novex Holland B ob. 20-40 WF 10x 
Din/20mm în laboratorul de Parazitologie și Helmintologie al Institutului de Zoologie.

\section{REZULTATE ȘI DISCUȚII}

În scopul determinării a infestaţiei cu diverse specii de ectoparaziţi au fost efectuate cercetări complexe în sectorul privat a Zonei de Centru a Moldovei, în perioada anilor 2014-2018 de pe 365 de păsări. Analiza datelor obţinute relevă, că păsările domestice în gospodăriile particulare sunt poliparazitate cu o gamă largă de diverse specii de ectoparaziţi: malofagi, purici și acarieni gamazizi (tab.1).

Poliparazitismul malofagian înregistrat la păsările domestice (găini, curci, raţe, gîști) este alcătuit din 13 specii de malofagi, iar la găini este constituit din 10 specii, dintre care specia Chelopistes meleagridis este ocazională.

O infestare moderată cu acarieni gamazizi: Dermanyssus gallinae și D. hirundinis s-a înregistrat pe corp la găini și curci, iar în cuiburi și așternuturi s-a stabilit o infestare masivă cu acești paraziţi. Nivelul infestării păsărilor domestice (per/corp), cu purici Ceratophylus gallinae și C.hirundinis este scăzut, în așternut s-a înregistrat o infestare masivă, iar cu specia Knemidocoptes mutans o infestare de la slabă până la masivă.

La raţe și gâști, în general, la palmipedele acvatice cu particularităţi biochimice specifice ale pielii, s-a stabilit o faună de ectoparaziţi mai săracă, comparativ cu cea a galinaceelor constituită din 3 specii de malofagi: Anaticola crassicornis, Anatoecus dentatus și Anatoecus icterodes.

Tabelul 1. Diversitatea speciilor de ectoparaziţi la păsările domestice din Zona de Centru a Moldovei

\begin{tabular}{|l|l|l|}
\hline Nr. & Denumirea paraziţilor & Gazda \\
\hline \multicolumn{3}{|c|}{ MALOFAGI } \\
\hline 1 & Cuclotogaster heterographus (Nitzsch, 1866) & Găini (+), curci (++) \\
\hline 2 & Chelopistes meleagridis (Linnaeus, 1758) & Găini (+), curci (+++) \\
\hline
\end{tabular}




\begin{tabular}{|l|l|l|}
\hline 3 & Eomenacanthus stramineus (Nitzsch, 1818) & Găini (+++), curci (+) \\
\hline 4 & Goniocotes gallinae (De Geer, 1778) & Găini (+++) \\
\hline 6 & Goniocotes maculatus (Taschenberg, 1882) & Găini (+), \\
\hline 7 & Goniodes dissimilis (Nitzsch, 1818) & Găini (+) \\
\hline 8 & Menopon gallinae ( Linnaeus, 1758) & Găini (+++) \\
\hline 9 & Menacanthus cornutus (Schomer, 1913) & Găini (++) \\
\hline 10 & Menacanthus pallidulus (Neumann, 1912) & Găini (+) \\
\hline 11 & Lipeurus caponis (Linnaeus, 1758) & Găini (+) \\
\hline 12 & Anaticola crassicornis (Scopoli, 1763) & Raţe (+++), gâște (+++) \\
\hline 13 & Anatoecus dentatus (Scopoli, 1763) & Raţe (+++), gâște (+++) \\
\hline 14 & Anatoecus icterodes (Nitzsch, 1818) & Raţe (++), gâște (++) \\
\hline \multicolumn{2}{|c|}{ PURICI } & $\begin{array}{l}\text { Găini (+), } \\
\text { în așternutul cuiburilor (+++) }\end{array}$ \\
\hline 15 & Ceratophylus gallinae (Schrank) & $\begin{array}{l}\text { Găini (+), } \\
\text { în așternutul cuiburilor (+++) }\end{array}$ \\
\hline 16 & C. hirundinis (Curtis) & $\begin{array}{l}\text { Găini (++), curci (+), } \\
\text { în așternutul cuiburilor (+++) }\end{array}$ \\
\hline \multicolumn{2}{|l|}{ ACARIENI PARAZITIFORMI } \\
\hline 17 & Dermanyssus gallinae (Redi) & $\begin{array}{l}\text { Găini (+), curci (+), } \\
\text { în așternutul cuiburilor }\end{array}$ \\
\hline 18 & D. hirundinis (Herm.) & $\begin{array}{l}\text { Găini (+++), fazani (+), } \\
\text { prepeliţe (++), curci (++) }\end{array}$ \\
\hline 19 & Knemidocoptes mutans &
\end{tabular}

Legendă: (+++) - infestare masivă; (++) - infestare moderată; (+) - infestare slabă

Totodată, pe parcursul anilor 2014-2018 au fost efectuate cercetări parazitologice la păsările sălbatice de interes cinegetic (fazani (72 ex.), prepeliţe (154 ex.), gîști (22 4ex.), lebede (18 ex.) și raţe (31 ex.)), întreţinute în captivitate și în natură în diverse biotopuri ale Republicii Moldova. În rezultatul investigaţiilor parazitologice efectuate s-a stabilit, că păsările sălbatice (fazani, prepeliţe, gâști, raţe) sunt poliparazitate cu o gamă largă de diverse specii de ectoparaziţ: 10 specii de malofagi, 2 specii de puric și 3 specii de acarieni parazitiformi (tab.2). 
Tabelul 2. Diversitatea speciilor de ectoparaziţi la păsările domestice şi sălbatice

\begin{tabular}{|c|c|c|c|}
\hline \multirow{2}{*}{$\begin{array}{l}\text { Nr. } \\
\text { d/o }\end{array}$} & \multirow[t]{2}{*}{ Gazda } & \multicolumn{2}{|c|}{ Speci de ectoparaziţi } \\
\hline & & specifici & comuni \\
\hline 1 & 2 & 3 & 4 \\
\hline \multicolumn{4}{|c|}{ Malofagi } \\
\hline \multirow{3}{*}{1.} & \multirow{3}{*}{ Fazani } & Cuclotogaster cinereus & \\
\hline & & Goniocotes chrysocephalus & \\
\hline & & Goniodes colchici & \\
\hline 1 & 2 & 3 & 4 \\
\hline \multirow{5}{*}{2.} & \multirow{5}{*}{ Fazani, prepeliţe, găini } & & $\begin{array}{l}\text { Eomenacanthus strami- } \\
\text { neus }\end{array}$ \\
\hline & & & Menopon gallinae \\
\hline & & & Goniocotes gallinae \\
\hline & & & Goniodes dissimilis \\
\hline & & & Lipeurus caponis \\
\hline \multirow{4}{*}{3.} & \multirow{4}{*}{ Prepeliţ̧e } & Cuclotogaster heterographus & \\
\hline & & Menopon gallinae & \\
\hline & & Menacanthus stramineus & \\
\hline & & Eomenacanthus stramineus & \\
\hline \multirow{3}{*}{4.} & \multirow{3}{*}{$\begin{array}{l}\text { Prepeliţe, găini, fazani, } \\
\text { curci }\end{array}$} & & $\begin{array}{l}\text { Eomenacanthus strami- } \\
\text { neus }\end{array}$ \\
\hline & & & Menopon gallinae \\
\hline & & & $\begin{array}{l}\text { Cuclotogaster heterogra- } \\
\text { phus }\end{array}$ \\
\hline \multirow{9}{*}{5.} & \multirow{9}{*}{ Găini } & Cuclotogaster heterographus & \\
\hline & & Eomenacanthus stramineus & \\
\hline & & Goniocotes gallinae & \\
\hline & & Goniocotes maculatus & \\
\hline & & Goniodes dissimilis & \\
\hline & & Menopon gallinae & \\
\hline & & Menacanthus pallidulus & \\
\hline & & Menacanthus cornutus & \\
\hline & & $\begin{array}{l}\text { Lipeurus caponis } \\
\text { Chelopistes meleagridis }\end{array}$ & \\
\hline 6. & Curci & Chelopistes meleagridis & \\
\hline
\end{tabular}




\begin{tabular}{|c|c|c|c|}
\hline \multirow[t]{5}{*}{7.} & \multirow[t]{5}{*}{ Curci, găini } & & $\begin{array}{l}\text { Eomenacanthus strami- } \\
\text { neus }\end{array}$ \\
\hline & & & Goniocotes gallinae \\
\hline & & & $\begin{array}{l}\text { Cuclotogaster heterogra- } \\
\text { phus }\end{array}$ \\
\hline & & & Menopon gallinae \\
\hline & & & Chelopistes meleagridis \\
\hline \multirow[t]{3}{*}{8.} & \multirow[t]{3}{*}{ Gâști } & Anaticola crassicornis & \\
\hline & & Anatoecus dentatus & \\
\hline & & Anatoecus icterodes & \\
\hline \multirow[t]{3}{*}{9.} & \multirow{3}{*}{$\begin{array}{l}\text { Gîști, lebede negre, lebe- } \\
\text { de albe, gâscă de Cana- } \\
\text { da, raţe }\end{array}$} & & Anaticola crassicornis \\
\hline & & & Anatoecus dentatus \\
\hline & & & Anatoecus icterodes \\
\hline \multicolumn{4}{|c|}{ Purici } \\
\hline 10. & Găini & Ceratophylus gallinae & \\
\hline 11. & $\begin{array}{l}\text { Găini, prepeliţe,curci, } \\
\text { fazani }\end{array}$ & & Ceratophylus gallinae \\
\hline 12. & Rîndunică & Ceratophylus hirundinis & \\
\hline 13. & $\begin{array}{l}\text { Rîndunică, găini, curci, } \\
\text { prepeliţe, fazani }\end{array}$ & & Ceratophylus hirundinis \\
\hline \multicolumn{4}{|c|}{ Acarieni parazitiformi } \\
\hline 14. & Găini & Dermanyssus gallinae & \\
\hline 15. & $\begin{array}{l}\text { Găini, fazani, prepeliţe, } \\
\text { curci }\end{array}$ & & Dermanyssus gallinae \\
\hline 16. & Rîndunică & Dermanyssus hirundinis & \\
\hline 17. & $\begin{array}{l}\text { Găini,fazani, prepeli- } \\
\text { ţe,curci }\end{array}$ & & Dermanyssus hirundinis \\
\hline 18. & $\begin{array}{l}\text { Găini, fazani, prepeli- } \\
\text { ţe,curci }\end{array}$ & & Knemidocoptes mutans \\
\hline
\end{tabular}

Analiza datelor expuse în tabelul 2 denotă, că structura poliparazitară malofagiană înregistrată la fazani este constituită din 3 specii specifice (Cuclotogaster cinereus, Goniocotes chrysocephalus, Goniodes colchici) și 5 specii comune (Eomenacanthus stramineus, Menopon gallinae, Goniodes gallinae, Goniodes dissimilis, Lipeurus caponis), care parazitează și pe păsările domestice din Republica Moldova.

La fel, au fost înregistrare 2 specii de purici comune pentru găini, picheri și curci (Ceratophylus gallinae, Ceratophylus hirundinis) și 3 specii de acarieni parazitiformi, comune pentru păsările sălbatice și domestice 
(Dermanyssus gallinae, Dermanyssus hirundinis, Knemidocoptes mutans).

La prepeliţe s-a înregistrat 4 specii de malofagi (Eomenacanthus stramineus, Menacanthus stramineus, Menopon gallinae, Cuclotogaster heterographus), dintre care 3 specii comune pentru păsările domestice (Eomenacanthus stramineus, Menopon gallinae, Cuclotogaster heterographus), 2 specii de purici (Ceratophylus gallinae, Ceratophylus hirundinis) și 3 specii de acarieni parazitiformi (Dermanyssus gallinae, Dermanyssus hirundinis, $\mathrm{K}$ nemidocoptes mutans) comune și pentru păsările domestice.

Cercetările parazitologice efectuate la palmipedele acvatice (raţe, gîști, lebăde) relevă, că păsările sălbatice luate în studiu sunt infestate cu 3 specii de malofagi (Anaticola crassicornis, Anatoecus dentatus, Anatoecus icterodes), care au fost înregistrate și la păsările domestice (raţe, gîști).

Așadar, poliparazitismul înregistrat la păsările sălbatice se datorează, probabil, faptului, că ele într-o perioadă scurtă de timp parcurg distanţe mari, de la un continent la altul, cu diverse zone climaterice. Totodată, cu ele transportând în/pe corp o gamă bogată de agenți parazitari, inclusiv malofagi, purici, acarieni etc. ce duce la formarea și menținerea focarelor de boli parazitare, ceea ce și s-a stabilit.

\section{CONCLUZII}

1. S-a determinat, că poliparazitismul malofagian înregistrat la păsările domestice (găini, curci, raţe, gîști) este alcătuit din 13 specii de malofagi (Cuclotogaster heterographus, Eomenacanthus stramineus, Goniocotes gallinae, Goniocotes maculatus, Goniodes dissimilis, Menopon gallinae, Menacanthus pallidulus, Menacanthus cornutus, Lipeurus caponis, Chelopistes meleagridis, Anaticola crassicornis, Anatoecus dentatus, Anatoecus icterodes). La găini au fost înregistrate 10 specii de malofagi (Cuclotogaster heterographus, Eomenacanthus stramineus, Goniocotes gallinae, Goniocotes maculatus, Goniodes dissimilis, Menopon gallinae, Menacanthus pallidulus, Menacanthus cornutus, Lipeurus caponis, Chelopistes meleagridis), dintre care specia Chelopistes meleagridis este ocazională, 2 specii de purici (Ceratophylus gallinae, Ceratophylus hirundinis) și 3 specii de acarieni gamazizi (Dermanyssus gallinae, Dermanyssus hirundinis, Knemidocoptes mutans).

2. S-a stabilit, că păsările sălbatice de interes cinegetic (fazani, prepeliţe, gâști, raţe sălbatice) sunt poliparazitate cu o gamă largă de diverse 
specii de ectoparaziţ: 10 specii de malofagi, (Cuclotogaster cinereus, Goniocotes chrysocephalus, Goniodes colchici, Cuclotogaster heterographus, Eomenacanthus stramineus, Menopon gallinae, Menacanthus stramineus, Anaticola crassicornis, Anatoecus dentatus, Anatoecus icterodes), dintre care 9 specii (Cuclotogaster heterographus, Eomenacanthus stramineus, Menopon gallinae, Goniocotes gallinae, Goniodes dissimilis, Lipeurus caponis, Anaticola crassicornis, Anatoecus dentatus, Anatoecus icterodes) sunt comune pentru păsările domestice, 2 specii de purici (Ceratophylus gallinae, Ceratophylus hirundinis) și 3 specii de acarieni parazitiformi (Dermanyssus gallinae, Dermanyssus hirundinis, Knemidocoptes mutans), care au fost stabilite și la păsările domestice.

Investigațiile au fost realizate în cadrul proiectului 15.817.02.12 F, finanțat de Consiliul Suprem pentru Știință și Dezvoltare Tehnologică al Academiei de Științe a Moldovei.

\section{BIBLIOGRAFIE}

1. Luncașu M., Zamornea M. Procedeu de colectare a ectoparaziţilor de la păsări /Brevet de invenţie. 3441 G2, MD, A01 M 1/20 BOPI nr, 12/2007.

2. Olteanu Gh. ș. a. Poliparazitismul la om, animale, plante și mediu. București, $2001.812 \mathrm{p}$.

3. Toderaș I. ș. а. Роль птиц и эктопаразитов в подАержании, возобновлении и возможном появлении новых очаговых зоонозных инфекций. Сообщение 1. În: Buletinul Academiei de Știinţe a Moldovei. Știinţele vieţii. 2008, nr 2, p. 4-10.

4. Zamornea M., Bondari L., Anghel T., Buza, V. Extensivitatea invaziei cu ectoparaziți la găini în gospodării cu diverse tehnologii de întreținere în RepublicaMoldova. Măsuri de profilaxie și tratament. Simpozion știinţific internaţional: 40 ani de invăţămant superior medical veterinar în Republica Moldova, 09-10 octombrie 2014. Lucrări știinţifice, Chișinău, 2014, vol. 40, p. 219-222.

5. Zamornea M., Erhan D., Rusu Ș. etc. Fauna ectoparazitară la fazani în Republica Moldova, măsurele de profilaxie și tratament //În culegerea Simpozionului știinţific Internaţional „ProtecţiaPlantelor - Realizări și Perspective”, Chișinău, 27-28 octombrie 2015, p. 48-51.

6. Аубинина М. Паразитологическое исследование птиц. М.-^.: ИзА-во АН СССР $1955,157 \mathrm{c}$. 